\title{
Tuberculose no século XXI: \\ Revisão de literatura com relato de caso em cavidade oral
}

\author{
Tuberculosis in the 21st Century: \\ Literature review with case report in oral cavity
}

\section{Vânia do Carmo Rodrigues}

Especialista em Estomatologia pela Unigranrio / RJ.

Professora do curso de pós-graduação de Estomatologia da Unigranrio / RJ.

\section{Luiz Carlos Moreira}

Mestre em Doenças sexualmente transmissíveis pela Universidade Federal Fluminense / RJ.

Coordenador do curso de pós-graduação de Estomatologia da Unigranrio / RJ.

\section{Roger Silva Lima}

Graduado em Odontologia pela Unigranrio / RJ.

Estágio no Departamento de Medicina Oral da Universidade de Santiago de Compostela / Espanha.

\section{Simone de Queiroz Chaves Lourenço}

Doutora em Patologia Bucal pela Universidade de São Paulo / SP.

Professora de Patologia Bucal da Faculdade de Odontologia da Universidade Federal Fluminense / RJ.

\section{Rodrigo F. de B. Resende}

Doutor em Odontologia pela Universidade Federal Fluminense / RJ.

Professor de Cirurgia Oral Menor da Faculdade de Odontologia da Universidade Federal Fluminense / RJ.

Endereço para correspondência:

Rua Professor José de Souza Herdy, 1160 - Jardim Vinte e Cinco de Agosto, Duque de Caxias - RJ, 25071-202

Tel: (21) 3219-4040 
Email: vania.do.carmo@hotmail.com

\section{RESUMO}

A Tuberculose (TB) é uma entidade de infecção bacteriana, granulomatosa, crônica e sistêmica. O agente causador, Mycobacterium Tuberculosis, pode acometer vários órgãos vitais, com maior frequência os pulmões, podendo comprometer os rins e os gânglios linfáticos, e ocasionalmente pode ser responsável por manifestações hepáticas, neurológicas e osteomioarticulares. Os sintomas clássicos da TB pulmonar incluem: tosse persistente, produtiva ou não, com muco e eventualmente sangue (hemoptise), febre vespertina, sudorese noturna e perda de peso ponderal. Na maioria dos indivíduos a infecção primária resulta apenas em um nódulo localizado, fibrocalcificado, situado no local inicial de desenvolvimento. No entanto, micro-organismos vivos podem estar presentes nestes nódulos e permanecerem latentes por muitos anos. Apenas 5 a $10 \%$ dos pacientes com TB progridem para infecção ativa e um estado de imunossupressão coexistente é frequentemente o responsável. Em raras situações, a TB ativa pode ocorrer diretamente de uma infecção primária. No entanto a doença ativa costuma desenvolver-se em fase mais tardia da vida, a partir de uma reativação do micro-organismo em uma pessoa previamente infectada. Tal reativação é caracteristicamente associada ao comprometimento do sistema de defesa do hospedeiro, sendo denominada de Tuberculose Secundária. O objetivo é realizar uma revisão da literatura sobre o tema e descrever um caso clínico de um paciente do sexo masculino, leucoderma, 35 anos de idade, com lesão em rebordo alveolar e lábio inferior com $6 \mathrm{~cm}$ em seu maior diâmetro, encaminhado a clínica de Estomatologia da Unigranrio / RJ, onde foi realizado o diagnóstico de TB e o paciente tratado da lesão sem as possíveis complicações desta doença.

PALAVRAS-CHAVE: Tuberculose; Micobacterium Tuberculosis; HIV; Lesões orais. 


\begin{abstract}
Tuberculosis (TB) is a bacterial, granulomatous, chronic and systemic infection entity. Caused by Mycobacterium tuberculosis, it most often affects the lungs, and can compromise the kidneys and lymph nodes, occasionally it may be responsible for hepatic, neurological and osteomyoarticular manifestations. The classic symptoms of pulmonary TB include: persistent cough, productive or otherwise, with mucus and eventually blood (hemoptosis), evening fever, night sweats and weight loss.

In most individuals the primary infection results only in a localized, fibrocalcified nodule located at the initial site of development. However, living microorganisms may be present in these nodules and remain dormant for many years. Only 5-10\% of TB patients progress to active infection and a coexisting immunosuppressive state is often responsible. In rare situations, active TB can occur directly from a primary infection. However, the active disease usually develops later in life, from a reactivation of the microorganism in a person previously infected. Such reactivation is characteristically associated to the compromise of the host defense system, being denominated Secondary Tuberculosis. The objective is to carry out a review of the literature on the subject and to describe a clinical case of a male patient, leucoderma, 35 years old, with lesion in the alveolar ridge and lower lip with $6 \mathrm{~cm}$ in its largest diameter, referred to the clinic of Stomatology of Unigranrio / RJ, where the diagnosis of TB was made and the patient treated with the lesion without the possible complications of this disease.
\end{abstract}

KEY WORDS: Tuberculosis; Mycobacterium tuberculosis; HIV; Oral lesions. 


\section{INTRODUÇÃO}

A Tuberculose é um importante problema de saúde pública. Todo ano mais de 9 milhões de casos novos são identificados e aproximadamente 2 milhões de mortes são registradas em todo o mundo. Apesar de existirem medicamentos eficazes disponíveis, a TB é uma doença temida devido a crescente resistência aos medicamentos e a coinfecção com vírus da imunodeficiência humana (HIV) (AJANTHA et al 2013; SHARMA 2013).

A característica principal da infecção pelo HIV é a progressiva destruição dos linfócitos T CD4+, que possui uma função crucial na resposta imune ao Mycobacterium Tuberculosis e no diagnóstico imunológico da TB (TEIXEIRA 2017). Devido à essa imunossupressão e consequentemente deficiência em conter o crescimento do Mycobacterium Tuberculosis nos pulmões, ocorre uma disseminação hematológica e consequentemente envolvimento de um ou mais sítios extrapulmonares, mais frequentemente em pacientes imunossuprimidos, principalmente aqueles infectados por HIV.

A TB ao atingir outros órgãos é chamada de Tuberculose Extrapulmonar (TBEP), que pode ocorrer exclusivamente ou concomitante à forma pulmonar (FERRARI et al 2014). Não é raro o envolvimento de cabeça e pescoço. As regiões extrapulmonares mais comuns na cabeça e pescoço são os nódulos linfáticos cervicais, seguido da laringe e ouvido médio. Regiões muito menos comuns são: cavidade nasal, nasofaringe, cavidade oral, glândulas parótidas, esôfago e coluna vertebral. 


\section{REVISÃO DE LITERATURA}

\section{Histórico}

Existem relatos de TB em ossos pré-históricos encontrados na Alemanha 8.000 a. c.. Hipócrates definiu TB como uma doença natural e chamou tísica pelo caráter de esgotamento físico (do grego phthisikos), ou seja, que traz consumpção. (PINA 2000; PUCPR 2017).

As primeiras noções de profilaxia foram realizadas por médicos italianos dos séculos XIV e XV, indicando o isolamento dos doentes e de seus pertences.

No séculos XVII e XVIII deu-se início a exploração anatômica dos pulmões com Manget, Morton e Morgani, com identificação de estruturas que lembravam tubérculos nos pacientes mortos pela tísica, a partir daí o nome Tuberculose (PINA 2000; PUCPR 2017).

Todo o século XIX foi um século de tristeza para artistas em geral, escritores, pois era a época de morrer precocemente. Em 1865 cobaias foram inoculadas com material de tubérculos e em 1882, Robert Kock descobre seu grande causador. Posteriormente, em 1885 Roentgen impulsionou os estudos através do raios-X (PINA 2000; PUCPR 2017).

Em 1922, ao voltar de uma temporada de estudos em Paris, Manoel Dias de Abreu ao encontrar a cidade do Rio de Janeiro acossada por uma dramática epidemia de Tuberculose retomou seus trabalhos em busca de desenvolver uma técnica de diagnóstico precoce, amplo uso e baixo custo. Finalmente em 1936 as primeiras imagens nítidas que permitiam ver sinais de sinais de Tuberculose foram obtidas. Combinando técnicas de radiologia e fotografia a máquina emitia um feixe de raios- $\mathrm{X}$ que se tornava fluorescente e produzia uma imagem visível a olho nu, captada por uma câmera fotográfica (FIORAVANTI 2017).

Até 1940 eram realizados tratamentos cirúrgicos como ressecção dos pulmões e pneumotórax terapêutico na tentativa de controle da doença. Com o surgimento dos antibióticos obteve-se a cura. A estreptomicina foi descoberta em 1944 e a isoniazida 
em 1945 teve comprovada a eficácia contra a TB. Na década de 1960 é introduzida a terapêutica ideal com o esquema tríplice realizado até hoje.

A TB nos nossos dias é uma doença curável, cuja prevalência diminuiu consideravelmente após a introdução da estreptomicina e da poliquimioterapia. No entanto, não é um problema totalmente resolvido devido ao seu ressurgimento espetacular.

A partir de 1990, tem sido relacionado ao aparecimento da epidemia de AIDS, contribuindo, também, para isso, o surgimento de cepas multidroga-resistente (PUCPR 2017).

No Brasil, o mal avança, chamando atenção a situação da cidade do Rio de Janeiro, sendo as regiões de Manguinhos e Jacarezinho as mais afetadas. É uma doença que atinge mais de 10 mil pessoas por ano no estado do Rio de Janeiro. Segundo o Ministério da Saúde (2016), a taxa de incidência da doença é a segunda maior do país, atrás apenas do Estado do Amazonas. Na capital, ao contrário do que poderia se imaginar, o desenvolvimento não reduziu os números - o Rio enfrenta uma endemia de Tuberculose. Esta é uma das mais antigas e mortais doenças infecciosas da história da Humanidade que resiste e se alimenta de problemas sociais do Rio, como moradias precárias, amontoadas e sem ventilação, que mal recebem a luz do sol, onde o saneamento é quase inexistente e falta assistência médica de qualidade.

Nas duas comunidades mais flageladas e abandonadas pelo poder público, as taxas são mais que o triplo das outras regiões da cidade. Em Manguinhos, por exemplo, chega a 337,4 por 100 mil habitantes, e no Jacarezinho que tem população de 39.041 moradores registrou 130 casos em 2016, a proporção também é assustadora, 332,9 por mil habitantes. Superam os de países africanos, como Congo (324) e Serra Leoa (307) (GALDO 2017).

Além da situação observada nas comunidades, nos presídios os índices também são alarmantes. A Tuberculose atinge 1500 a cada 100 mil presos no Rio de Janeiro. Pesquisa da Fiocruz aponta que a incidência do Complexo de Gericinó é bem mais alta que a média do país. Nos presídios brasileiros, Ministério da Saúde (2015), essa 
incidência foi de 932 infectados em 100 mil. Um dos fatores é essa política de encarceramento sem uma infraestrutura capaz de albergar pessoas em condições minimamente dignas. Há ainda o fato de as pessoas viverem dentro do mesmo ambiente, sabendo que estamos falando de uma doença que é transmissível de pessoa para pessoa e está ligada a condições imunológicas do próprio indivíduo, destacando que presos infectados pelo vírus HIV ou portadores diabetes, por exemplo, têm mais facilidade em contrair a TB (BACELAR 2017).

\section{Transmissão}

Após a inalação de partículas infectantes do BAAR, determina-se o complexo primário (complexo de gohn), geralmente em terço médio do pulmão no hemisfério direito. Ocorrendo uma disseminação linfática regional, seguida de distribuição hematogênica. A transmissão ocorre por via aérea e é inter-humana, através da inalação do agente causador, eliminado ao meio ambiente pelo doente com TB pulmonar.

As formas extrapulmonares de TB, embora não representem fator de risco no que diz respeito a transmissão ganham cada vez mais importância em virtude do aumento da sua incidência, independentemente de ocorrerem em países desenvolvidos ou não, fato este estritamente relacionada a epidemia de AIDS.

Quanto ao contágio estima-se que uma pessoa bacilífera infecte de 10 a 15 pessoas por ano. Ele se dá através das gotículas de Flugge, as mais pesadas vão ao chão, as mais leves, evaporão rapidamente, chegam aos brônquios liberando o núcleo seco que é o núcleo de Wells, com menos de $5 \mathrm{~mm}$ de diâmetro contendo de 1 a 3 bacilos, onde conseguem se multiplicar. A partir daí forma-se o Foco de Gohn, ou seja, o encapsulamento do bacilo com formação da lesão granulomatosa. Esse foco é formado em 4 semanas. Através dele sucederá a disseminação para um gânglio satélite, seguindo a distribuição hematogênica para todo organismo. Complexo primário ou de Ranke é o conjunto de foco, linfonodo e linfangite.

A imunidade adquirida consegue bloquear a doença em até $95 \%$ dos casos. Em $5 \%$ a evolução não é contida, há formação do caseo, e a doença evolui a partir da primo infecção, chamando-se também de Tuberculose primária (5 anos iniciais de infecção). 
Clinicamente pode ser aguda e grave, que é menos comum ou insidiosa e lenta, mais comumente.

TB secundária é comum em adultos, crescimento lento do caseo com lesões cavitárias e fibrose, corresponde à reativação de foco quiescente. Sendo comum em seguimentos posteriores do ápice pulmonar. A cavitação pode evoluir para cura ou para complicação, fístulas ou aneurismas (TEIXEIRA 2017; PUCPR 2017).

Desta forma, quando as bactérias causadoras da TB entram em contato com o hospedeiro, três situações podem ocorrer: (AJANTHA et al 2013) a resposta imune do hospedeiro elimina completamente o agente; (ALVES 2012) o sistema imune não consegue controlar a replicação dos bacilos, causando a TB primária; ou (BACELAR 2017) o sistema imune, consegue conter as bactérias em granulomas, de forma latente podendo provocar a TB pós-primária ao escapar do sistema imune (FERRARI et al 2014).

\section{Diagnóstico}

Os métodos atuais de diagnóstico apresentam problemas como: baixa sensibilidade da baciloscopia, longo tempo de realização das culturas microbiológicas, baixa especificidade do teste cutâneo com derivado proteico purificado (PPD) do Mycobacterium Tuberculosis.

A baciloscopia do escarro é o método utilizado rotineiramente para a identificação do bacilo-álcool-ácido-resistente (BAAR) da TB. Entetanto, esta técnica carece de sensibilidade, que oscila entre 30 a $80 \%$, com média de $60 \%$, em pacientes com cultura positiva. Além disso, não é capaz de discriminar a espécie de micobactéria.

A cultura para o bacilo da TB é um método mais sensível, pois detecta 70 a $89 \%$ dos casos, em média $80 \%$, e permite a identificação posterior da espécie através de testes bioquímicos. A limitação deste modo reside no tempo necessário, visto que o resultado de cultura fica disponível apenas 15 a 60 dias após a coleta do material respiratório. 
Teste tuberculínico/teste mantroux ou PPD: Apesar de sua importância não tem $100 \%$ de sensibilidade (porcentagem em indivíduos doentes com teste positivo) ou especificidade (porcentagem de indivíduos sadios que apresentam teste negativo). Em média 10 a $25 \%$ de pacientes com TB ativa não reagem, e sua especificidade também é variável (TEIXEIRA 2017; PUCPR 2017).

Esse teste tem sensibilidade diminuída em pacientes imunocomprometidos, pessoas recentemente infectadas e crianças muito jovens. A especificidade é baixa pois o PPD contém diversos antígenos amplamente compartilhados entre diferentes espécies de micobactéria. As taxas de falso negativo podem chegar a $66 \%$ em pacientes com AIDS.

O PPD não distingue, com segurança, pessoas vacinadas com BCG daquelas expostas a micobactérias do ambiente ou infectadas com M. Tuberculosis.

A técnica de aplicação (a mais utilizada é a técnica de mantoux) e o material utilizado são padronizados pela Organização Mundial da Saúde (OMS) e têm especificações semelhantes às usadas para a vacinação BCG. A injeção do líquido no antebraço faz aparecer uma pequena área de limites precisos, pálida e de aspecto pontilhado como casca de laranja.

A leitura da prova tuberculínica é realizada de 72 a 96 horas após a aplicação, medindo-se com régua milimetrada o maior diâmetro transverso da área de endurecimento palpável. O resultado, registrado em milímetros, sendo a medição superior a $5 \mathrm{~mm}$ indicativo de positividade.

Reação em Cadeia Polimerase (PCR) vem se mostrando como uma ferramenta adicional, juntamente com os métodos convencionais no diagnóstico de TBEP. Coloração Ziehl Neelson (ZNS) e Cultura no meio de Lowenstein - Lensen (LIM) (TEIXEIRA 2017; PUCPR 2017).

Na TBEP as investigações microbiológicas convencionais são menos confiáveis, podendo retardar o diagnóstico. Uma abordagem molecular (PCR) é certamente uma ferramenta de maior eficácia e também pode ser utilizada para identificar droga 
resistente. O PCR é um teste eficaz, de alta sensibilidade e especificidade (AJANTHA et al 2013).

O aparelho Xpert MTB/RIF fornece um teste rápido de diagnóstico e avalia a sensibilidade aos medicamentos. É usado para detectar, a partir do escarro, a presença do DNA do bacilo Mycobacterium tuberculosis e de mutação que indique resistência ao antibiótico Rifampicina. A metodologia Xpert foi aprovada, no início de 2014, para implementação no Sistema Único de Saúde (SUS) em todo o país (RAVEENDRAN 2016; SIALA et al 2017; ULLAH et al 2017).

O exame radiográfico fornece informações úteis ao diagnóstico, porém a disponibilidade de exames de imagem mais avançados como a tomografia computadorizada, a laparoscopia e a endoscopia auxiliam na localização anatômica mais exata dos comprometimentos. A radiografia de tórax é um método de grande importância na investigação de TB. Diferentes achados apontam para a suspeita de doença em atividade ou doença do passado, além do tipo e extensão do comprometimento pulmonar. $\mathrm{Na}$ TB primária o foco pulmonar habitualmente corresponde à pequena opacidade parenquimatosa, frequentemente unifocal, acometendo mais lobos superiores, na infância, e lobos médio e inferior, em adultos, parece haver uma preferência mais pelo pulmão direito. Na TB secundária, os segmentos mais comprometidos são o anterior dos lobos superiores e o medial do lobo médio (Síndrome do lobo médio). Na TB primária, ocasionalmente, o foco pulmonar primário pode drenar o caseo liquefeito, causando uma cavitação. Quando está drenagem é feita para vaso sanguíneo, há uma grave disseminação miliar (MINISTÉRIO DA SAÚDE 2011).

Existe certa dificuldade no diagnóstico definitivo da TBEP, uma vez que os sintomas e os resultados dos exames de imagens podem ser vagos. Muitas vezes é necessário recorrer a outros testes de diagnóstico, sendo alguns invasivos, tais como: ultrassom e PAAF (punção aspirativa por agulha fina) usado para coletar amostras biológicas para o diagnóstico (NEVILLE et al 2004).

As biópsias e histopatológicos têm grande importância para esclarecimento de lesões que simulam malignidade (diagnóstico diferencial) (ZHANG et al 2017). No 
histopatológico observa-se uma reação de hipersensibilidade mediada por células responsável pela apresentação clássica da tuberculose. Áreas de infecção demonstram formação de granulomas que são coleções circunscritas de histiócitos epitelióides, linfócitos e células gigantes multinucleadas do tipo Langhans frequentemente com necrose caseosa central (LIMA 2011; PINA 2000; REDDY et al 2013) Colorações especiais, como a de Ziehl-Neelsen, ou colorações ácido-resistentes são utilizadas para identificação do micro-organismo (MINISTÉRIO DA SAÚDE 2011; NEVILLE et al 2004).

Habitualmente os macrófagos rodeiam os bacilos, diferenciando-se em células eptelióides que se agregam formando granulomas. De uma a três semanas depois, coincidindo com o desenvolvimento do fenômeno de hipersensibilidade, começam a surgir nos granulomas já bem formados focos de necrose, tendendo para a coalescência, com o clássico aspecto caseoso, havendo, em paralelo, um envolvimento dos granulomas por linfócitos e fibroblastos, contribuindo para o limitar geográfico da doença (PINA 2000).

\section{Tratamento}

A transmissibilidade está presente desde os primeiros sintomas respiratórios, caindo rapidamente após o início do tratamento. Após 15 dias de tratamento, e havendo melhoria clínica, o paciente pode ser considerando não infectante, em alguns casos de resistência às drogas recomenda-se também negativação da baciloscopia.

A terapia antituberculose é aplicada, e aos 2 meses, os nódulos desaparecem, permanecendo assintomática no seguimento ambulatorial.

Na TBEP recomenda-se usar os mesmos regimes de antibiótico com duração de 6 meses e somente prolongar a medicação quando houver envolvimento do sistema nervoso e espondilite tuberculosa com acometimento neurológico.

A TB é uma doença grave, porém curável em praticamente $100 \%$ dos casos, desde que os princípios da quimioterapia sejam seguidos. 
A associação medicamentosa adequada, doses corretas, uso por tempo suficiente, com supervisão da tomada dos medicamentos. São os meios para evitar a resistência bacteriana e o desenvolvimento da resistência às drogas, assegurando assim a cura do paciente.

O esquema básico de tratamento realizado para os paciente, consiste em um regime diário de Rifampicina/ Ioniazida/ Pirazinamida/Etambutol, sendo a tomada dos medicamentos observada diretamente em pelo menos três dias da semana durante os primeiros dois meses e uma observação por semana até o final do tratamento. Rifampicina/ isoniazida/Pirazinamida/ Etamutol, por 2 meses e Rifampicina/ Isoniazida por 4 meses, completando 6 meses de terapia.

Deve se ter em mente que a Estreptomicina e a Estionamida, são fármacos utilizados nos casos de resistência a múltiplos medicamentos (MINISTÉRIO DA SAÚDE 2011).

\section{Vacinação}

A vacina BCG (Bacillus Calmette Guérin) começou a ser testada em 1925 e ficou conhecida como a primeira vacina do século XX. A BCG confere poder de proteção às formas graves de primo infecção pelo M. Tuberculosis.

No Brasil, a vacina BCG é prioritariamente indicada em crianças de 0 a 4 anos de idade, sendo obrigatória para menores de 1 ano, como dispõe a portaria $\mathrm{n}^{\circ} 452$, de 06/12/76, do Ministério da Saúde (MINISTÉRIO DA SAÚDE 2011; FUNDAÇÃO ATUALPHO DE PAIVA 2017).

Recomenda-se a revacinação nas crianças com idade de 10 anos, podendo esta dose ser antecipada para 6 anos. Não há necessidade de revacinação caso a primeira dose tenha ocorrido aos 6 anos de idade ou menos (MINISTÉRIO DA SAÚDE 2011).

\section{RELADO DE CASO CLÍNICO}

Paciente sexo masculino, leucoderma, 35 anos de idade, residente da comunidade de Manguinhos no Rio de Janeiro / RJ, foi encaminhado a clínica de Estomatologia da Unigranrio por seu dentista clínico, apresentando uma lesão ulcerada 
em rebordo alveolar e lábio inferior com cerca de $6 \mathrm{~cm}$ em seu maior diâmetro, onde o mesmo relatava queixas álgicas no local, odinofagia e perda de peso nos últimos meses (Figuras 1).

Inicialmente foram solicitados exames laboratoriais com resultado negativo para HIV e sífilis e uma radiografia póstero-anterior de tórax, onde se visualizou evidenciando o aspecto de tuberculose com padrão miliar (Figuras 2), sendo confirmado através do teste rápido molecular. Além disso, foi realizado o PCR que detectou o DNA do Mycobacterium Tuberculosis e registrou também a sensibilidade a Rifampicina.

Em seguida foi realizada uma biópsia incisional de cerca de $1 \mathrm{~cm}$ em região anterior de rebordo alveolar e material encaminhado para exame histopatológico no LABA / UFF, confirmando a lesão em um período de quinze dias.

Após o diagnóstico, o paciente foi encaminhado à Fiocruz de Manguinhos /RJ, onde recebeu tratamento com a medicação padrão para o tratamento, composta por Isoniazida, Rifampicina e Etambutol, onde no período de trinta dias de uso da medicação, houve a regressão das lesões em cavidade oral (Figura 3 A e B).

\section{DISCUSSÃO}

A forma extrapulmonar de Tuberculose é mais difícil de ser diagnosticada, por ser menos comum e/ou por não ser devidamente relatada aos profissionais de saúde. Pode acometer locais de difícil acesso e, devido à natureza destes, alguns bacilos podem causar grandes danos; é responsável por $1 / 5$ de todos os casos de TB em pacientes imunocompetentes e atinge cerca de $50 \%$ dos casos de pacientes imunodeprimidos com Tuberculose. Este envolvimento é produzido por disseminação linfática e hematogênica do bacilo M. Tuberculosis para outros órgãos. Ocorre em 40\% das lesões de tuberculose. Embora não transmissível, é uma importante causa de morbidade (AJANTHA et al 2013; ALVES 2012; PUROHIT 2015).

O termo TBEP inclui Tuberculose linfática, pleural, meningea, pericárdica, esquelética, gastrointestinal e TB miliar. As linfadenites (ganglionares) e derrames pleurais são as apresentações mais comuns (LAPAUSA 2015; NEVILLE et al 2004; 
REDDY et al 2013) A forma ganglionar, devido ao mimetismo que mantém com outras patologias, leva comumente à falha ou atraso na obtenção do diagnóstico correto, sendo um grande desafio ao clínico, requerendo um elevado índice de suspeição associado a um exame clínico complexo e cuidadoso, bem como exames complementares adequados para se obter o diagnóstico definitivo (NENO et at 2014).

A TB pode apresentar lesões incontáveis no pulmão, como pequenas opacidades medindo de 1 a 3 mm de diâmetro, que se disseminam difusamente através de sistema vascular atingindo órgãos, cérebro, medula, meninges e pericárdio. Esta apresentação é denominada Tuberculose Miliar (MINISTÉRIO DA SAÚDE 2011; NEVILLE et al 2004).

Qualquer sistema orgânico pode ser atingido, inclusive o sistema linfático, pele, sistema nervoso central, rins e trato gastrointestinal. Quando há envolvimento da pele denomina-se Lúpus Vulgar (NEVILLE et al 2004).

Mal de Pott, também denominada espondilite tuberculosa. É uma forma de apresentação extrapulmonar onde a coluna vertebral é afetada., atingindo, com maior frequência, as regiões torácica e lombar; se manifesta com dor progressiva associada a alterações neurológicas sugestivas de comprometimento medular. A complicação mais importante é a compressão medular na fase ativa da infecção, podendo resultar em paraplegia (PINA 2000).

Lesões bucais na Tuberculose são incomuns, na maioria dos casos surge como uma úlcera crônica e indolor. Menos frequente, as apresentações compreendem áreas leucoplásicas nodulares, granulares, ou (raramente) firmes. A maior parte das lesões apresenta infecção secundária à lesão pulmonar inicial. As lesões bucais secundárias estão prioritariamente na língua, seguindo palato e mucosas dos lábios e gengival, ou ainda como osteomielite tuberculosa da mandíbula, são evidenciadas clinicamente em 0,5 a 1,5\% dos casos de TB (GUPTA 2011; KAHAMMISSA et al 2011; PÉREZ et al 2014; RAUL et al 2015; REDDY et al 2013). Essas lesões podem se apresentar em forma de úlceras com aspecto crateriforme com halo eritematoso, bordas sangrantes, apresentando tamanhos variados podendo medir de 2 a 3 centímetros de diâmetro, brancacentas, com fundo regular e localização usualmente na parte anterior e superfície 
ventral da língua. Essas lesões raramente serão apresentações primárias da doença (PÉREZ et al 2014).

Não está claro se as lesões bucais evoluem por disseminação hematogênica ou por exposição à secreção catarral contaminada (NEVILLE et al 2004). Estudos sugerem que as manifestações bucais são infrequentes devido ao fluxo contínuo da saliva que dificulta a deposição dos bacilos, e no caso de atravessarem a mucosa oral são fagocitados e incorporados à circulação sem provocar lesão (PÉREZ et al 2014). Outras pesquisas mostram que a contaminação ocorrerá quando houver úlceras traumáticas em contato com o escarro infectado, pois geralmente a barreira epitelial intacta e a propriedade antibacteriana da saliva impedem o acometimento da cavidade oral (KAHAMMISSA et al 2011; REDDY et al 2013).

Nas adenopatias cervicais, denominadas escrófulas, podem ocorrer abscessos que fistulam material necrótico e caseoso. Essas lesões podem sugerir malignidades (PÉREZ et al 2014). Segundo Genovese, podem ser observadas úlceras indolores que crescem lentamente rodeadas por um característico conjunto de manchas amarelas denominadas sinal de Trèlat (GENOVESE 1996).

\section{CONCLUSÃO}

A TB continua sendo um problema social e de saúde, afetando milhares de pessoas anualmente. A vacina BCG, usada no controle profilático, mostra-se incapaz no controle da progressão da doença. $\mathrm{O}$ diagnóstico da $\mathrm{TB}$ em seus estágios iniciais aliado a poliquimioterapia podem contribuir para o controle da disseminação da doença. Os métodos apresentam problemas, tais como: baixa sensibilidade da baciloscopia; longo tempo de realização da cultura microbiológica; baixa especificidade do teste do derivado purificado de micro-organismo. Novos métodos de biologia molecular têm se mostrado como uma ferramenta importante no controle da TB. Porém enquanto houver miséria e HIV, estaremos longe do controle desta enfermidade. 


\section{FIGURAS}

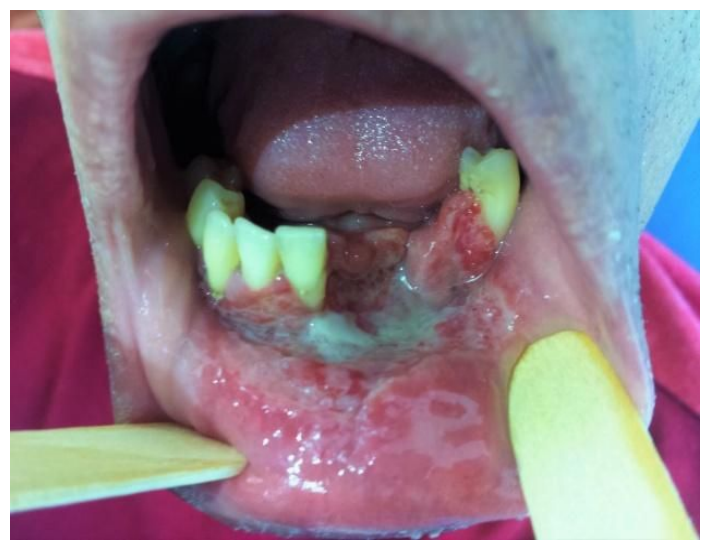

Figuras 1: Aspecto intraoral da lesão, evidenciando uma região ulcerada crateriforme com fundo amarelado em rebordo alveolar e lábio inferior.

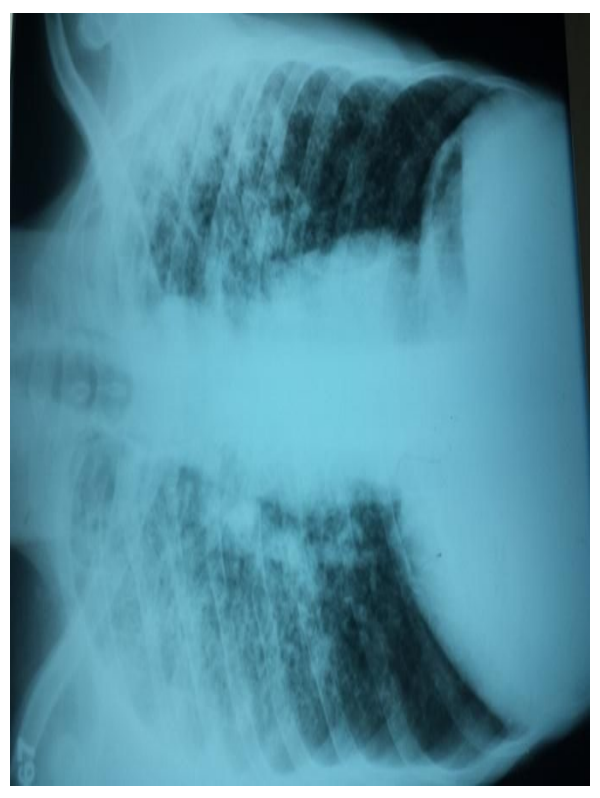

Figura 2: Radiografia póstero-anterior de tórax, evidenciando tuberculose com padrão miliar. 

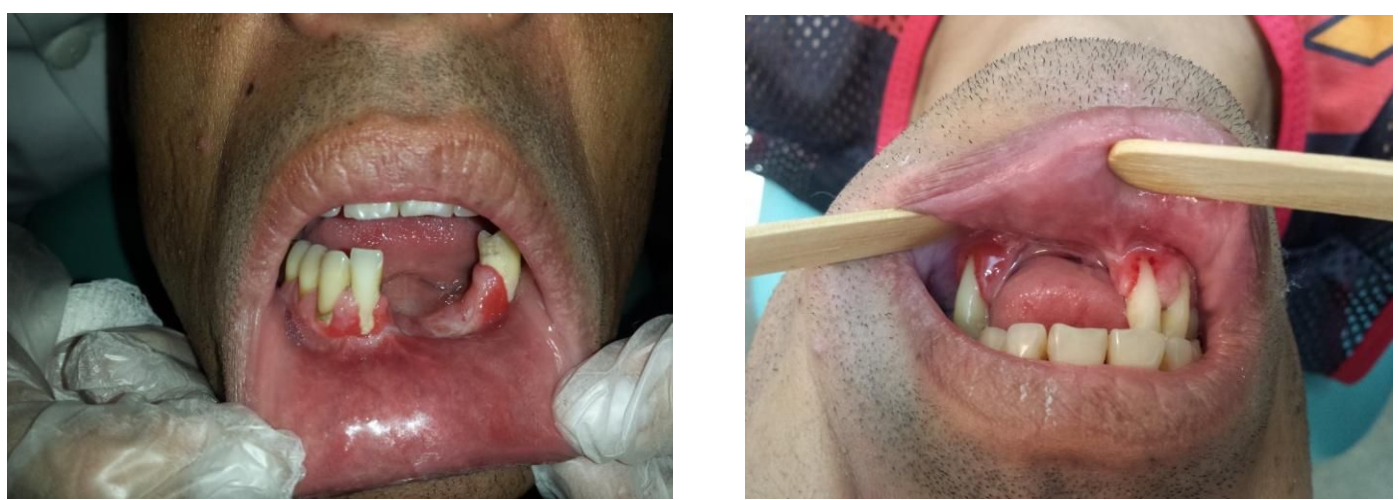

Figura 3 A e B: Aspecto intraoral após trinta dias do uso da medicação, evidenciando a regressão das lesões após tratamento.

\section{REFERÊNCIAS BIBLIOGRÁFICAS}

1. Ajantha GS, Hetty PC, Kulkarni D et al. PCR as a Dignostic Tool for Extra-pulmonary e Tuberculosis. Journal od clinical and diagnostic research. Karnataka, Índia, 2013; 8: 1012-1015.

2. Sharma SK, Mohan A. Tuberculosis: From a incurable scourge to a curable disease - journey over a millenium. Indian J. Med. Res., Índia, 2013; 137: 455-493.

3. Teixeira HC, Abramo C, Munk ME. Diagnóstico Imunológico da Tuberculose: problemas e estratégias para o sucesso. Jornal Brasileiro de Pneumologia, Brasil, $2017 ; 33-34$.

4. Ferrari AO, Aguiar B, Wilhelm CM et al. Diagnóstico da Tuberculose: uma revisão. Revista Liberato, Novo Hamburgo, 2014; 15:105-212.

5. Pina J. A Tuberculose na Viragem do Milénio. 2ed. Lisboa: Editora Lidel, 2000; 10-11. 
6. Tuberculose

(TB).

2017.

Disponível

em www.pucpr.br/saúde/laboratórios/pneumologia/trabalhos/tuberculose.doc. Acesso em 22 de outubro de 2017 as 17:38 hs.

7. Fioravanti C. Retratos dos Pulmões. Revista Pesquisa FAPESP, ed.259, Brasil, 2017.

8. Galdo R, Marenco D. Tuberculose, o mal que avança: quadro da doença piora na cidade do Rio de Janeiro, Manguinhos e Jacarezinho são as áreas mais afetadas. Jornal O Globo, Caderno Rio, p. 12, 15 de out.2017.

9. Bacelar C. Tuberculose atinge 1.500 a cada 100 mil presos: Pesquisa da Fiocruz aponta que incidência no Complexo do Gericinó é bem mais alta que a media do país. Jornal O Globo, Coluna Rio, p. 14, 18 dez.2017.

10. Alves G, Silva R, Haygert C Extrapulmonary Tuberculosis. Revista Científica da Ordem dos Médicos. Acta Médica Portuguesa, 2012; 58.

11. Raveendran R, Wattaz C. Utility of multiplex real time PCR in tbs diagnosis of extrapulmonary tuberculosis. The Brazilian Journal Infectious Diseases, Brasil, 2016; 20: 235-241.

12. Siala M, Smaoui S, Taktak W et al. First-time detection and identification on the Mycrobacterim tuberculosis Complex members in extraordinary tuberculosis clinical samples in south Tunisia by a single tube tetraplex real-tinme PCR assay. Gerd Pluschke, swiss Tropical and public Health Institute, Switzerland; 2017.

13. Ullah I, Javaid A, Masud H et al. Rapid detection of Mybacterium tuberculosis and rifampicin resistance in extrapulmonary tuberculosis and sputum smear-negative pulmonary suspects using Xpert MTB/RIF. Journal of Medical Microbiology. 2017. Disponível em www.microbiologysociety.org. Acesso em 08 de outubro de 2017`as 17:02 hs. 
14. Ministério da Saúde. Manual de Recomendações para o Controle da Tuberculose no Brasil. Secretaria de Vigilância em Saúde, Brasília, 2011; 41- 60.

15. Nevile B, Damm DD, Allen CM et al. Patologia Oral e Maxilofacial. $2^{\text {a }}$ Ed. Rio de Janeiro: Editora Guanabara Koogan, 2004; 167-169.

16. Zhang X, Wang J, Wu Y et al. Tuberculosis with atypical manifestations involving multiple sites of the oral cavity: a case study. India Journal of Dermatology Venereology and Leprology, China, 2017; 83: 116-118.

17. Lima EP, Estudo clínico, morfológico e imuno-histoquímico de série de casos de Tuberculose pleural e ganglionar. Universidade Federal do Pará. Programa de Pós-Graduação em Doenças Tropicais, 2011.

18. Reddy RS, Ramya K, Kanth MR, et al. Disguised ulcer of lip and buccal mucosa- rare clinical manifestation as tuberculosis: a case report. Archives of Oral Research, Índia, 2013; 8: 243-248.

19. Qualidade do BCG produzido pela FAP é reconhecida pela Organização Mundial de Saúde. 2017. Disponível em www.fundacaoataulphodepaiva.com.br. Acesso em setembro de 2017.

20. Purohit M, Mustafa T. Laboratory Diagnosis of Extra-pulmonary Tuberculosis (EPBT) in Esource - constrained Setting: Satae of the Art, Challenges and the Need. Journal of clinical and Diagnostic Research, Índia, 2015; 9:1- 6.

21. Lapausa, MR, Saldanha AM, Asensio A N. Tuberculosis extrapulmonar, uma revisión. Rev. Esp. Sanid. Penit., Universidade Hospital La Paz, Barcelona, $2015 ; 17$.

22. Neno M, Rocha C, Sargento D et al. Tuberculose Ganglionar: desafio diagnóstico. Arquivos de Medicina, Porto, 2014; 28.

23. Gupta G, Khattak BP, Agrawal V. Primary Gengival tuberculosis: A rare clinical entity - Contemporary Clinical Dentristy, Índia, 2011; 2. 
24. Kahammissa RAG, Wood NH, Meyerov R. et al. Primary Oral Tuberculosis as an indicator of HIV infection: case report. Pathology Research International, South Africa, 2011.

25. Pérez, RP, Prieto VA, H Torres PR et al. Tuberculose Pulmonar e Lingual. Apresentação de um caso. Revista Colombiana Gastroenterologia, Bogotá, 2014; 19.

26. Raul PM, Emil PI, Mirian O et al. Morphological aspects in tuberculosis of orla cavity - our experience and a review of the literature attempt. Rom J. Morphol Embriol., Romênia, 2015; 56: 967-987.

27. Genovese WJ. Exames Complementares na Clínica Odontológica. Editora Fundação Petrópolis. 1996; 84.

28. Datta M, Smieja M.. Evidence - based Infectious Diseases. 2a Ed. Editora Wiley, 2009; 7: 86-97 